\title{
Low Perceived Social Support Is Associated with CD8+CD57+ Lymphocyte Expansion and Increased TNF- $\alpha$ Levels
}

\author{
Alfredo Copertaro, ${ }^{1}$ Massimo Bracci, ${ }^{2}$ Nicola Manzella, ${ }^{2}$ Mariella Barbaresi, ${ }^{1}$ \\ Benedetta Copertaro, ${ }^{1}$ and Lory Santarelli ${ }^{2}$ \\ ${ }^{1}$ Healthcare Workers Service, ASUR, Area Vasta No. 2, 60025 Loreto, Italy \\ ${ }^{2}$ Occupational Medicine, Department of Clinical and Molecular Science, Polytechnic University of Marche, \\ Torrette, 60020 Ancona, Italy \\ Correspondence should be addressed to Massimo Bracci; m.bracci@univpm.it
}

Received 10 February 2014; Accepted 10 April 2014; Published 27 April 2014

Academic Editor: Peter P. Egeghy

Copyright (C) 2014 Alfredo Copertaro et al. This is an open access article distributed under the Creative Commons Attribution License, which permits unrestricted use, distribution, and reproduction in any medium, provided the original work is properly cited.

Social support has been supposed to have a positive impact on the function of the immune system. However, the relationship between perceived social support and immune function has not yet been fully investigated. In this cross-sectional study, we investigated the link between perceived social support and lymphocyte subpopulations and cytokines. 232 healthy subjects provided a blood sample and completed the Multidimensional Scale of Perceived Social Support (MSPSS) questionnaire. Lymphocyte immunophenotypes and cytokines were determined. Significantly increased CD8+CD57+ lymphocytes and TNF- $\alpha$ levels were found in group with low perceived social support. Multivariate linear regression corrected for possible confounders confirmed a significant role of perceived social support in predicting the number of CD8+CD57+ lymphocyte and TNF- $\alpha$ levels. This study supports the association between perceived social support and immune function. In particular, poor social support may be related to a state of chronic inflammation sustained by CD8+CD57+ lymphocyte expansion and increased TNF- $\alpha$ levels.

\section{Introduction}

Social support from various sources, such as family, friends, organizations, and coworkers, has been linked to many benefits for both physical and mental health [1-3]. Perceived social support refers to the insight that support would be available if needed. It is well documented that perceived social support has not only a direct effect on health but also an indirect one by buffering stress [4]. Epidemiological studies indicate that individuals with low levels of social support have higher mortality rates, especially as a result of cardiovascular disease [5-7]. Although more research is needed, there is also evidence linking support to lower cancer and infectious disease mortality [8-10].

Psychological stress and negative emotions that could be a consequence of low social support can also have an impact on the immune system [11-14].

Furthermore, alterations in immune activity may be related to increased morbidity and mortality in populations exposed to adverse psychosocial factors such as poor social networks, low socioeconomic status, and portrayed psychological distress [15-17].

Little is currently known about the direct effects of perceived social support on lymphocyte subpopulations and cytokines.

In this cross-sectional study, we investigated the link between perceived social support and immune parameters, including lymphocyte immunophenotypes and cytokines, in a group of healthy subjects.

\section{Materials and Methods}

2.1. Participants and Sampling. Participants in the study were nurses from the local National Health Service Hospital Unit, Ancona, Italy. The study was carried out in accordance with the Declaration of Helsinki's ethical standards. Being part of standard occupational health surveillance it needed no 
formal approval by the local ethics committee, which was nevertheless consulted and which granted an informal authorization. Inclusion criteria were age $<60$ years, no infectious disorders or chronic medical diseases, no history of major psychiatric disorders, and no current or recent treatment with drugs affecting the immune system (e.g., corticosteroids, cytostatics, immunosuppressors, and immunomodulators). 232 nurses, meeting the selection criteria, agreed to participate in the study and gave their written informed consent. They were asked to refrain from exercising, smoking, eating, drinking alcohol, or taking medications for at least $12 \mathrm{~h}$ before sampling.

A blood sample was collected between 08:30 and 09:30 am. Blood was analyzed for leukocyte count, immunophenotype, and cytokines. After blood collection, the nurses completed a self-administered standardized questionnaire on lifestyle and habits. Perceived social support was evaluated by the validated 12-item Multidimensional Scale of Perceived Social Support questionnaire (MSPSS). It is scored on a 7point scale, where higher scores indicate greater perceived availability of support from family, friends, and other sources [18].

\subsection{Laboratory Analysis}

2.2.1. Immunophenotype Analysis. Immunophenotype analysis was performed on fresh whole blood within $2 \mathrm{~h}$ of collection using a direct immunofluorescence cytofluorimetric assay. Flow cytometric acquisition was performed on FACScalibur using MultiSet software (Becton Dickinson, San Jose, USA). At least 10,000 events for each sample were acquired. The proportions of cells expressing CD19+ (B cells), CD3+CD4+ (T helper lymphocytes), CD8+ (cytotoxic/suppressor T lymphocytes), CD8+CD57+ (T lymphocytes with cytotoxic activity), and CD3-CD16+CD56+ (NK cells) were calculated. Absolute values were obtained based on lymphocyte counts provided by an automated Haematology Analyzer (Gen-S, Beckman-Coulter, Fullerton, CA, USA).

2.2.2. Cytokine Analysis. Proinflammatory cytokines (IL-1 $\beta$, IL-6, INF- $\gamma$, and TNF- $\alpha$ ) were analyzed using a multiplex sandwich ELISA (SearchLight, Pierce Biotechnology, Rockford, IL, USA) according to the manufacturer's instructions. Each sample was tested in duplicate. Results are expressed as $\mathrm{pg} / \mathrm{mL}$.

2.3. Statistical Analysis. The values of continuous variables were expressed as median and 25th-75th percentile while ordinal variables were expressed as percentages. The participants' MSPSS score was classified into two categories using the median value as the cutoff. The Mann-Whitney $U$ test for continuous variables or the Chi-square test for dichotomous or categorical variables was used to evaluate differences between low and high MSPSS score groups. In order to protect against Type I errors, differences in studied parameters were evaluated with the Bonferroni-corrected MannWhitney $U$ test. Rho Spearman's correlation was applied
TABLE 1: Socio-demographic characteristics of the MSPSS groups according to low $(<65.0)$ and high $(\geq 65.0)$ MPSS score.

\begin{tabular}{|c|c|c|}
\hline & Low MSPSS score & High MSPSS score \\
\hline $\begin{array}{l}\text { Age (years): median } \\
\text { (25th-75th percentile) }\end{array}$ & $40.0(33.0-44.0)$ & $37.0(34.0-40.0)^{*}$ \\
\hline Gender (\%): (male/female) & $18.4 / 81.6$ & $22.4 / 77.6$ \\
\hline $\begin{array}{l}\text { Job seniority (years): } \\
\text { median ( } 25 \text { th-75th } \\
\text { percentile) }\end{array}$ & $15.0(10.0-22.0)$ & $14.0(8.0-17.8)^{*}$ \\
\hline $\begin{array}{l}\text { BMI }\left(\mathrm{Kg} / \mathrm{m}^{2}\right): \text { median } \\
(25 \mathrm{th}-75 \text { th percentile })\end{array}$ & $23.0(21.8-25.0)$ & $22.0(21.0-24.0)^{*}$ \\
\hline $\begin{array}{l}\text { Subjects taking physical } \\
\text { exercise }(\%)\end{array}$ & 27.2 & 23.3 \\
\hline Shift-working nurses (\%) & 49.4 & 54.9 \\
\hline Alcohol drinkers (\%) & 40.4 & $25.0^{*}$ \\
\hline Smokers (\%) & 43.0 & 44.0 \\
\hline \multicolumn{3}{|l|}{ Marital status (\%) } \\
\hline Unmarried & 21.1 & 31.0 \\
\hline Cohabiting & 5.3 & 5.2 \\
\hline Married & 70.2 & 60.3 \\
\hline Divorced & 3.5 & 3.4 \\
\hline Subjects with offspring (\%) & 66.7 & 60.3 \\
\hline
\end{tabular}

to analyze the relationship between continuous parameters. Multivariate linear regression analysis was used to study the association between the MSPSS score and immune parameters, adjusting for sociodemographic characteristics. All the tests were two-tailed. A probability $P<0.05$ was considered statistically significant. Data analysis was performed with SPSS 19.0 for Windows (SPSS Inc., Chicago, IL, USA).

\section{Results}

The sociodemographic characteristics of the 232 participants stratified into 2 groups by MSPSS score are reported in Table 1. The low MSPSS score group showed a significantly higher age (median 40.0 versus 37.0 years), job seniority (15.0 versus 14.0 years), and BMI (23.0 versus $22.0 \mathrm{Kg} / \mathrm{m}^{2}$ ) and a higher prevalence of alcohol drinkers (40.4\% versus $25.0 \%$ ) compared to the high MSPSS score group. The lymphocyte subpopulation and cytokine values are reported in Table 2; no pathological value was found among the participants. Significantly increased CD8+CD57+ lymphocytes (median 163 versus 110 cells $/ \mathrm{mm}^{3}$ ) and TNF- $\alpha$ levels (median 22.6 versus $12.8 \mathrm{pg} / \mathrm{mL}$ ) were found in the low MSPSS score group compared to the high MSPSS score group.

CD8+CD57+ lymphocytes were negatively correlated with the MPSS score $(P<0.05)$ and positively correlated with CD8+ lymphocytes, CD3-CD56+CD16+ lymphocytes, and TNF- $\alpha(P<0.05)$ (Table 3$)$. TNF- $\alpha$ was negatively 
TABLE 2: Immune and cortisol values in the MSPSS groups according to low $(<65.0)$ and high $(\geq 65.0)$ MPSS score. Results are expressed as median (25th-75th percentile).

\begin{tabular}{|c|c|c|}
\hline & Low MSPSS score & High MSPSS score \\
\hline \multicolumn{3}{|l|}{ Lymphocyte subpopulation } \\
\hline Total Lymphocytes (cells/ $\mathrm{mm}^{3}$ ) & $2164(1778-2644)$ & $2298(1915-2661)$ \\
\hline CD19+ lymphocytes (cells $/ \mathrm{mm}^{3}$ ) & $269(185-358)$ & $269(193-351)$ \\
\hline $\mathrm{CD} 3+\mathrm{CD} 4+$ lymphocytes $\left(\right.$ cells $\left./ \mathrm{mm}^{3}\right)$ & $1077(866-1273)$ & $1159(897-1425)$ \\
\hline CD8+ lymphocytes (cells/mm $\left.\mathrm{mm}^{3}\right)$ & $558(443-795)$ & $596(490-686)$ \\
\hline CD8+CD57+ lymphocytes (cells $/ \mathrm{mm}^{3}$ ) & $163(95-222)$ & $110(73-173)^{*}$ \\
\hline CD3-CD56+CD16+ lymphocytes $\left(\right.$ cells $\left./ \mathrm{mm}^{3}\right)$ & $215(164-300)$ & $201(137-283)$ \\
\hline \multicolumn{3}{|l|}{ Cytokines } \\
\hline $\mathrm{IL}-1 \beta(\mathrm{pg} / \mathrm{mL})$ & $0.6(0.2-2)$ & $0.7(0.2-1.7)$ \\
\hline IL-6 (pg/mL) & $1.3(0.7-4.3)$ & $1.5(0.9-4.2)$ \\
\hline TNF- $\alpha(\mathrm{pg} / \mathrm{mL})$ & $22.6(7.5-46.1)$ & $12.8(6.0-23.4)^{*}$ \\
\hline INF- $\gamma(\mathrm{pg} / \mathrm{mL})$ & $2.6(1.6-3.9)$ & $2.7(1.3-3.8)$ \\
\hline
\end{tabular}

${ }^{*} P<0.05$ high versus low MSPSS score (Bonferroni-corrected Mann-Whitney $U$ test).

TABLE 3: Rho Spearman's correlation between CD8+CD57+ and TNF- $\alpha$ with MSPSS score and immune parameters.

\begin{tabular}{lcc}
\hline & CD8+CD57+ Lymphocytes (rho) & TNF- $\alpha$ (rho) \\
\hline MSPSS score & $-\mathbf{0 . 2 2 9}^{*}$ & $-\mathbf{0 . 2 6 9}^{*}$ \\
Lymphocyte subpopulation & & -0.016 \\
Total Lymphocytes & -0.102 & 0.001 \\
CD19+ lymphocytes & -0.121 & -0.010 \\
CD3+CD4+ lymphocytes & $\mathbf{0 . 4 7 1}^{*}$ & -0.012 \\
CD8+ lymphocytes & $\mathbf{0 . 3 2 4}^{*}$ & 0.011 \\
CD3-CD56+CD16+ lymphocytes & $\mathbf{1}$ & $\mathbf{0 . 1 7 3}^{*}$ \\
CD8+CD57+ lymphocytes & & \\
Cytokines & 0.121 & $\mathbf{0 . 6 9 5}^{*}$ \\
IL-1 $\beta$ & 0.113 \\
IL-6 & $\mathbf{0 . 1 7 3}^{*}$ \\
TNF- $\alpha$ & 0.044 & $\mathbf{0 . 5 4 0}^{*}$ \\
INF- $\gamma$ & & $\mathbf{0 . 7 0 6}^{*}$ \\
${ }^{*} P<0.05$. & &
\end{tabular}

TABLE 4: Multiple linear regression of CD8+CD57+ lymphocytes and TNF- $\alpha$ with MSPSS adjusted for socio-demographic characteristics.

\begin{tabular}{lcc}
\hline & CD8+CD57+ lymphocytes $(\beta)$ & TNF- $\alpha(\beta)$ \\
\hline MSPSS score & $-\mathbf{0 . 1 7 ^ { * }}$ & $-\mathbf{0 . 2 1 ^ { * }}$ \\
Age & 0.05 & 0.01 \\
Gender male & -0.03 & 0.17 \\
BMI & -0.07 & -0.05 \\
Alcohol drinkers & 0.13 & 0.09 \\
\hline
\end{tabular}

${ }^{*} P<0.05$.

correlated with the MSPSS score and positively correlated with CD8+CD57+ lymphocytes and all the studied cytokines.

Multivariate linear regression showed a significant role of MSPSS score in predicting the number of CD8+CD57+ lymphocytes $(\beta=-0.17, P<0.05)$ and TNF- $\alpha(\beta=-0.21$, $P<0.05)$ (Table 4$)$.

\section{Discussion}

Several studies have pointed out that a poor perceived social support may not only affect emotional well-being but also result in disease development $[19,20]$. Chronic and/or traumatic stress owing to low perceived social support may lead to a downregulation of the immune function. On the other hand, a good perceived social support is associated with a reinforcement of immunity [21]. Recently, Carroll and colleagues found that low social support was related to shorter leukocyte telomere length in older people, in agreement with the hypothesis that the social environment may contribute to cellular aging [22]. A possible effect of social support-induced chronic stress on alterations in cellular aging may be explained by polyclonal expansions of $\mathrm{T}$ lymphocytes CD8+CD57+ representing a marker of immune senescence. CD8+CD57+ lymphocytes are activated cytotoxic T lymphocytes at a terminal stage of their differentiation with evidence of immunological senescence and 
limited proliferative capacity [23-25]. The CD57 antigen is normally expressed only by a minority of human CD8+ $\mathrm{T}$ lymphocytes, but its expression increases during chronic immune activation [25]. There is growing evidence that the $\mathrm{CD} 8+\mathrm{CD} 57+$ population plays a significant role in various diseases associated with chronic immune activation such as cancer, chronic intracellular infections, and physiological age-related changes in the immune system status [23]. Our results show that a low level of social support is related to an expansion of CD8+CD57+ lymphocytes.

An increase in TNF- $\alpha$ levels was found in the low MSPSS score group compared to the high MSPSS score group. TNF- $\alpha$ is a key cytokine, which plays a critical role in tumor immunity as well as in immunity against infection. It is produced mainly by activated macrophages, although it can be produced by many other cell types, such as lymphocytes, NK cells, and neurons [26]. The primary role of TNF- $\alpha$ is in the regulation of immune cells. The deregulation of TNF- $\alpha$ production has been implicated in infectious disease [2729 ] and in a variety of human diseases including cancer [30-32], Alzheimer's disease [33], major depression [34], and inflammatory bowel disease [35]. TNF- $\alpha$ is deleterious to the host with regard to coping with autoimmune or chronic inflammatory diseases [36-38].

Although it has been reported that CD8+CD57+ lymphocytes may produce proinflammatory cytokines, such as TNF- $\alpha$ [39-42], our data indicate only a correlation between CD8+CD57+ lymphocytes and TNF- $\alpha$ levels without providing evidence of a direct relationship between these two immune parameters. Since CD8+CD57+ lymphocytes and/or TNF- $\alpha$ may sustain a state of chronic inflammation [23,37], poor social support should be taken into account in patients with autoimmune or chronic inflammatory diseases.

\section{Conflict of Interests}

The authors declare that there is no conflict of interests to report. The study was supported by ASUR Area Vasta 2 and Polytechnic University of Marche.

\section{References}

[1] M. Reblin and B. N. Uchino, "Social and emotional support and its implication for health," Current Opinion in Psychiatry, vol. 21, no. 2, pp. 201-205, 2008.

[2] B. N. Uchino, "Social support and health: a review of physiological processes potentially underlying links to disease outcomes," Journal of Behavioral Medicine, vol. 29, no. 4, pp. 377-387, 2006.

[3] B. N. Uchino, "Understanding the links between social support and physical health: a life-span perspective with emphasis on the separability of perceived and received support," Perspectives on Psychological Science, vol. 4, no. 3, pp. 236-255, 2009.

[4] P. A. Thoits, "Stress, coping, and social support processes: where are we? What next?" Journal of Health and Social Behavior, vol. 35, extra issue, pp. 53-79, 1995.

[5] J. Barth, S. Schneider, and R. von Känel, "Lack of social support in the etiology and the prognosis of coronary heart disease: a systematic review and meta-analysis," Psychosomatic Medicine, vol. 72, no. 3, pp. 229-238, 2010.
[6] L. F. Berkman, L. Leo-Summers, and R. I. Horwitz, "Emotional support and survival after myocardial infarction: a prospective, population-based study of the elderly," Annals of Internal Medicine, vol. 117, no. 12, pp. 1003-1009, 1992.

[7] K. Orth-Gomer, A. Rosengren, and L. Wilhelmsen, "Lack of social support and incidence of coronary heart disease in middle-aged Swedish men," Psychosomatic Medicine, vol. 55, no. 1, pp. 37-43, 1993.

[8] K. Ell, R. Nishimoto, L. Mediansky, J. Mantell, and M. Hamovitch, "Social relations, social support and survival among patients with cancer," Journal of Psychosomatic Research, vol. 36, no. 6, pp. 531-541, 1992.

[9] M. Lee and M. J. Rotheram-Borus, "Challenges associated with increased survival among parents living with HIV," American Journal of Public Health, vol. 91, no. 8, pp. 1303-1309, 2001.

[10] M. Pinquart and P. R. Duberstein, "Associations of social networks with cancer mortality: a meta-analysis," Critical Reviews in Oncology/Hematology, vol. 75, no. 2, pp. 122-137, 2010.

[11] M. Amati, M. Tomasetti, M. Ciuccarelli et al., "Relationship of job satisfaction, psychological distress and stress-related biological parameters among healthy nurses: a longitudinal study," Journal of Occupational Health, vol. 52, no. 1, pp. 31-38, 2010.

[12] M. Biondi and L.-G. Zannino, "Psychological stress, neuroimmunomodulation, and susceptibility to infectious diseases in animals and man: a review," Psychotherapy and Psychosomatics, vol. 66, no. 1, pp. 3-26, 1997.

[13] V. de Gucht, B. Fischler, and C. Demanet, "Immune dysfunction associated with chronic professional stress in nurses," Psychiatry Research, vol. 85, no. 1, pp. 105-111, 1999.

[14] A. Nakata, "Psychosocial job stress and immunity: a systematic review," Methods in Molecular Biology, vol. 934, pp. 39-75, 2012.

[15] L. André-Petersson, G. Engström, B. Hedblad, L. Janzon, and M. Rosvall, "Social support at work and the risk of myocardial infarction and stroke in women and men," Social Science and Medicine, vol. 64, no. 4, pp. 830-841, 2007.

[16] N. Schneiderman, G. Ironson, and S. D. Siegel, "Stress and health: psychological, behavioral, and biological determinants," Annual Review of Clinical Psychology, vol. 1, pp. 607-628, 2005.

[17] S. C. Segerstrom and G. E. Miller, "Psychological stress and the human immune system: a meta-analytic study of 30 years of inquiry," Psychological Bulletin, vol. 130, no. 4, pp. 601-630, 2004.

[18] B. Bruwer, R. Emsley, M. Kidd, C. Lochner, and S. Seedat, "Psychometric properties of the multidimensional scale of perceived social support in youth," Comprehensive Psychiatry, vol. 49, no. 2, pp. 195-201, 2008.

[19] S. Cohen, W. J. Doyle, D. P. Skoner, B. S. Rabin, and J. M. Gwaltney Jr., "Social ties and susceptibility to the common cold," Journal of the American Medical Association, vol. 277, no. 24, pp. 1940-1944, 1997.

[20] I. G. Sarason, B. R. Sarason, E. H. Potter III, and M. H. Antoni, "Life events, social support, and illness," Psychosomatic Medicine, vol. 47, no. 2, pp. 156-163, 1985.

[21] T. Miyazaki, T. Ishikawa, A. Nakata et al., "Association between perceived social support and Thl dominance," Biological Psychology, vol. 70, no. 1, pp. 30-37, 2005.

[22] J. E. Carroll, A. V. Diez Roux, A. L. Fitzpatrick, and T. Seeman, "Low social support is associated with shorter leukocyte telomere length in late life: multi-ethnic study of atherosclerosis," Psychosomatic Medicine, vol. 75, no. 2, pp. 171-177, 2013. 
[23] M. Strioga, V. Pasukoniene, and D. Characiejus, "CD8+CD28and CD8+CD57+ T cells and their role in health and disease," Immunology, vol. 134, no. 1, pp. 17-32, 2011.

[24] J. M. Brenchley, N. J. Karandikar, M. R. Betts et al., "Expression of CD57 defines replicative senescence and antigen-induced apoptotic death of CD8+ T cells," Blood, vol. 101, no. 7, pp. 27112720, 2003.

[25] P. Coppo, M. Buffet, F. Feger, and K. Lassoued, "Polyclonal CD8+/CD57+ T cell expansions: clinical significance," Presse Medicale, vol. 42, no. 3, pp. 327-337, 2013.

[26] L. C. Gahring, N. G. Carlson, R. A. Kulmer, and S. W. Rogers, "Neuronal expression of tumor necrosis factor alpha in the murine brain," NeuroImmunoModulation, vol. 3, no. 5, pp. 289303, 1997.

[27] J. P. Waters, J. S. Pober, and J. R. Bradley, "Tumour necrosis factor in infectious disease," Journal of Pathology, vol. 230, no. 2, pp. 132-147, 2013.

[28] F. C. Riché, B. P. Cholley, Y. H. Panis et al., "Inflammatory cytokine response in patients with septic shock secondary to generalized peritonitis," Critical Care Medicine, vol. 28, no. 2, pp. $433-437,2000$.

[29] M. F. Tosi, "Innate immune responses to infection," Journal of Allergy and Clinical Immunology, vol. 116, no. 2, pp. 241-249, 2005.

[30] F. Balkwill, "TNF- $\alpha$ in promotion and progression of cancer," Cancer and Metastasis Reviews, vol. 25, no. 3, pp. 409-416, 2006.

[31] J. P. Waters, J. S. Pober, and J. R. Bradley, "Tumour necrosis factor and cancer," Journal of Pathology, vol. 230, no. 3, pp. 241248, 2013.

[32] H. Zelova and J. Hosek, "TNF-alpha signalling and inflammation: interactions between old acquaintances," Inflammation Research, vol. 62, no. 7, pp. 641-651, 2013.

[33] W. Swardfager, K. Lanctt, L. Rothenburg, A. Wong, J. Cappell, and N. Herrmann, "A meta-analysis of cytokines in Alzheimer's disease," Biological Psychiatry, vol. 68, no. 10, pp. 930-941, 2010.

[34] Y. Dowlati, N. Herrmann, W. Swardfager et al., "A meta-analysis of cytokines in major depression," Biological Psychiatry, vol. 67, no. 5, pp. 446-457, 2010.

[35] A. J. Watson and K. R. Hughes, "TNF-alpha-induced intestinal epithelial cell shedding: implications for intestinal barrier function," Annals of the New York Academy of Sciences, vol. 1258, pp. $1-8,2012$.

[36] A. Albillos, L. Muñoz, M. Nieto, M. Úbeda, A. de-la-Hera, and M. Alvarez-Mon, "Systemic effects of TNF- $\alpha$ secreted by circulating monocytes and fatigue in cirrhosis," Hepatology, vol. 43, no. 6, p. 1399, 2006.

[37] M. Apostolaki, M. Armaka, P. Victoratos, and G. Kollias, "Cellular mechanisms of TNF function in models of inflammation and autoimmunity," Current Directions in Autoimmunity, vol. 11, pp. 1-26, 2010.

[38] S. M. Kerfoot, C. D’Mello, H. Nguyen et al., "TNF- $\alpha$-secreting monocytes are recruited into the brain of cholestatic mice," Hepatology, vol. 43, no. 1, pp. 154-162, 2006.

[39] K. C. Wai, M. Fann, and N.-P. Weng, "Generation and growth of CD28nullCD8+ memory T cells mediated by IL-15 and its induced cytokines," Journal of Immunology, vol. 177, no. 11, pp. 7802-7810, 2006.

[40] L. K. Chong, R. J. Aicheler, S. Llewellyn-Lacey, P. Tomasec, P. Brennan, and E. C. Y. Wang, "Proliferation and interleukin 5 production by CD8hiCD57+ T cells," European Journal of Immunology, vol. 38, no. 4, pp. 995-1000, 2008.
[41] E. H. Eylar, C. E. Lefranc, Y. Yamamura et al., "HIV infection and aging: enhanced interferon- and tumor necrosis factor-alpha production by the $\mathrm{CD} 8+\mathrm{CD} 28-\mathrm{T}$ subset," $B M C$ Immunology, vol. 2, no. 1, article 10, 2001.

[42] J. Kober, J. Leitner, C. Klauser et al., "The capacity of the TNF family members 4-1BBL, OX40L, CD70, GITRL, CD30L and LIGHT to costimulate human T cells," European Journal of Immunology, vol. 38, no. 10, pp. 2678-2688, 2008. 


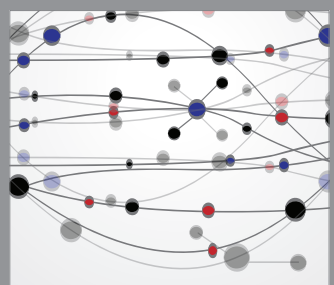

The Scientific World Journal
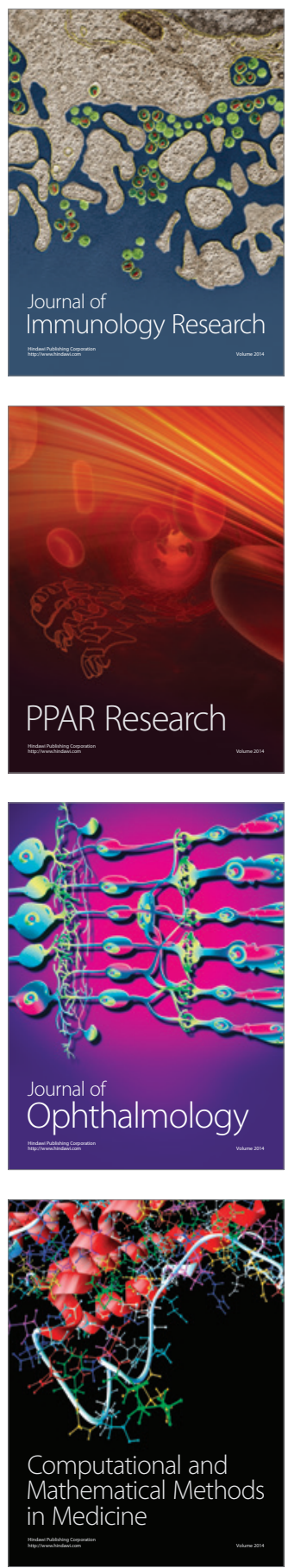

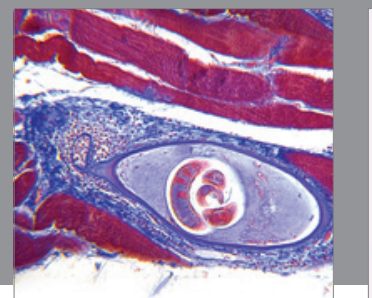

Gastroenterology

Research and Practice
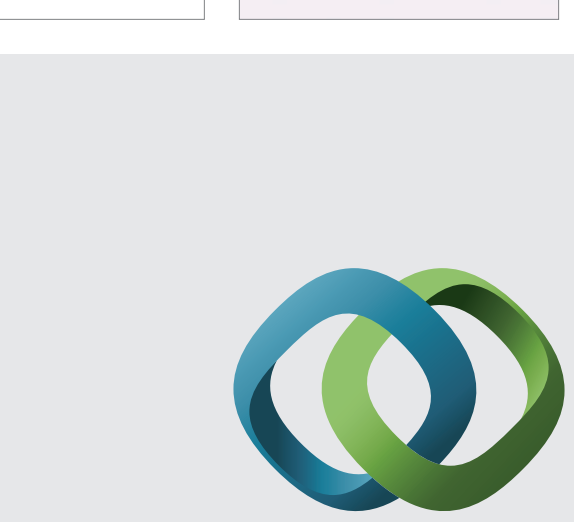

\section{Hindawi}

Submit your manuscripts at

http://www.hindawi.com
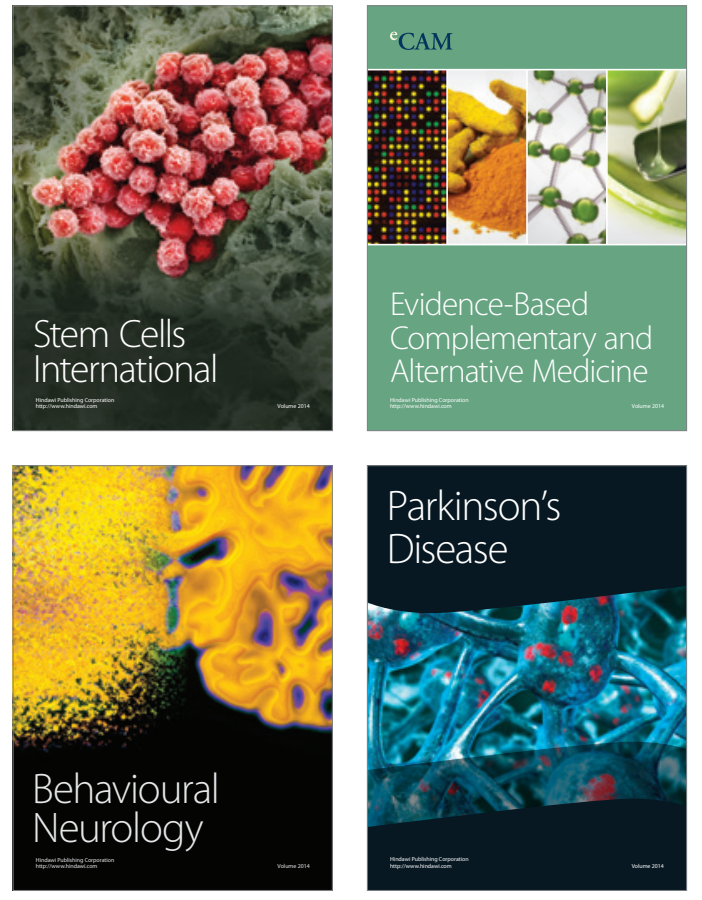
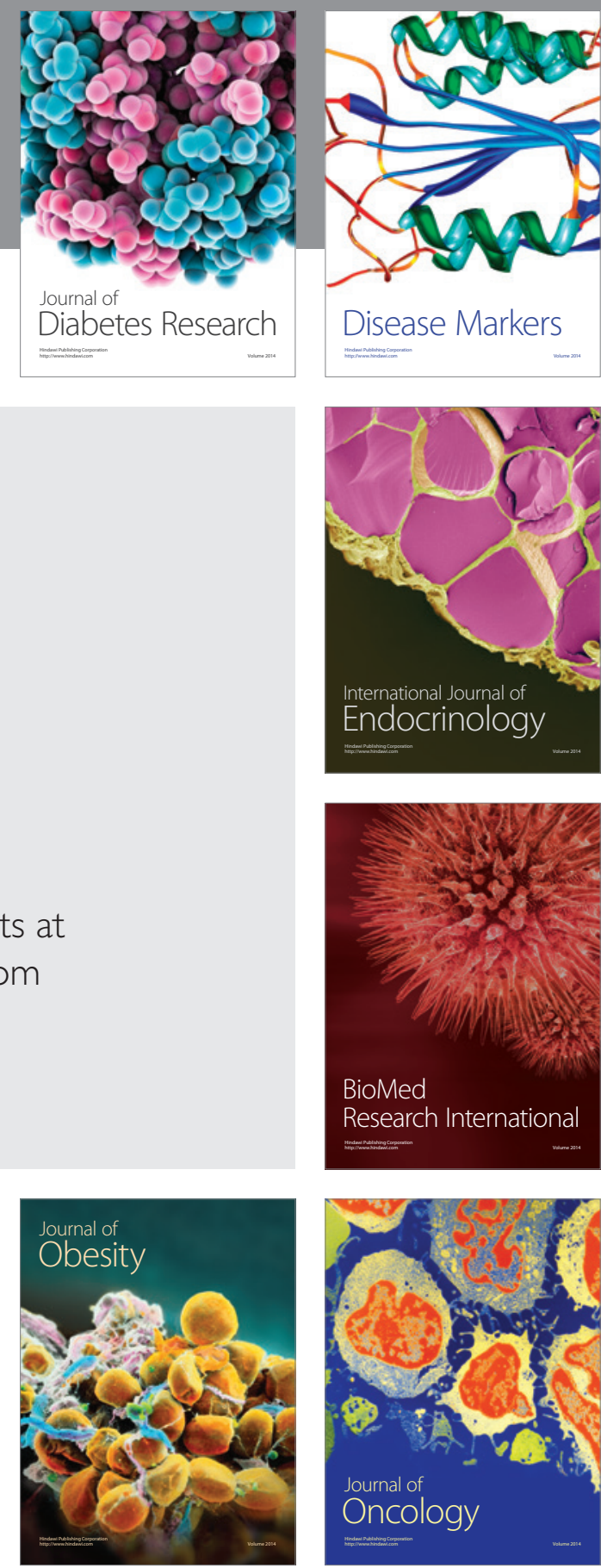

Disease Markers
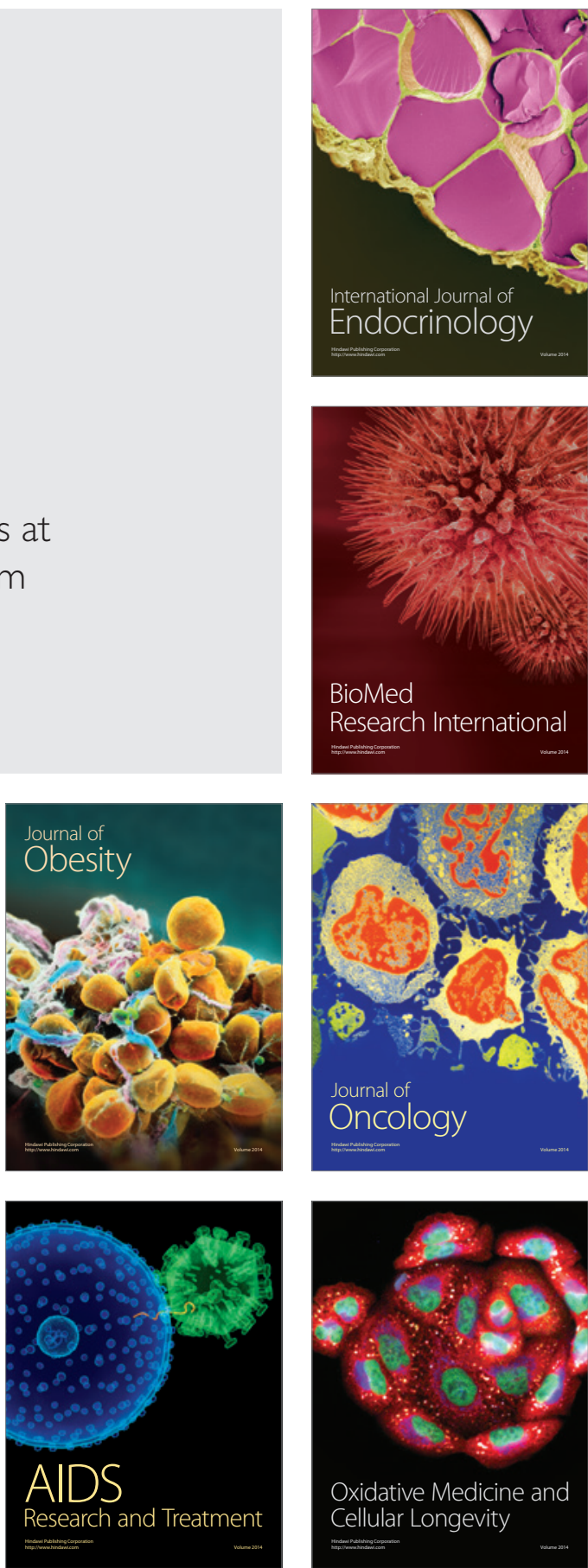